\title{
Coverage Evaluation of Vitamin A in Oil Using Lot Quality Technique among the Beneficiaries in a Block of West Bengal, India
}

\author{
Ritu Ghosh ${ }^{1}$, Saibendu Kumar Lahiri ${ }^{2}$, Surajit Lahiri ${ }^{3}$, Atanu Biswas ${ }^{3}$, Sutanuka \\ Santra $^{3}$, Poulomi Mukherjee ${ }^{3}$ \\ ${ }^{1}$ (Assistant Professor, Department of Community Medicine, R. G.Kar Medical College, Kolkata, West \\ Bengal,India) \\ ${ }^{2}$ (Professor \&Head, Department of Community Medicine, R.G.Kar Medical College, Kolkata, West \\ Bengal,India) \\ ${ }^{3}\left(2^{\text {nd }}\right.$ Year PGT, Department of Community Medicine, R. G.Kar Medical College, Kolkata, West Bengal,India)
}

\begin{abstract}
Background: VAD is a controllable public health and nutritional problem. Ensuring high supplementation coverage is critical for eliminating VAD. Objectives: $\boldsymbol{i})$ To assess the coverage of prophylactic Vitamin A in Oil among children aged 9-59 months in Amdanga Block ii) to find out the poorly performing villages (lots) iii)to determine the reasons for non receipt of a megadose. Methodology: A cross sectional study was conducted among the beneficiaries using LQT from December 2012- January 2013. The total and lot sample sizes were 663 and 9 respectively to be covered in 81 villages. The final sample size was 729. Decision value for a lot was set at 2. Data were collected from the Immunization card. The reasons were ascertained following WHO proforma. Results: Only $0.4 \%$ received age appropriate doses. Due to lack of supply for the last one year, children who missed $\leq 2$ doses were considered acceptable. The estimated coverage was $67.16 \%$; $59.2 \%$ lots had less satisfactory performance. The coverage with valid doses declined from the $1^{\text {st }}$ to the $9^{\text {th }}$ from $57.6 \%$ to $0 \%$. Children who missed $>2$ doses were significantly higher among those $\geq 36$ months than $<36$ months (78.6\% vs 21.4\%); no significant association was found with gender. Lack of supply was the commonest cause (68.18\%) of non receipt of a dose. Conclusion: BCC addressing both beneficiaries and providers is required to mitigate the lack of supply by improving the dietary intake, regular attendance to ICDS centre and early identification of ocular morbidities.
\end{abstract}

Keywords: Estimated coverage, Lot Quality Technique, Missed dose, Valid dose, Vitamin A supplementation

\section{Introduction}

Vitamin A is an essential micronutrient needed for the normal functioning of the visual system, growth and development, maintenance of epithelial cellular integrity and functioning of the immune system. Severe deficiency of vitamin A is known to produce corneal xerosis or keratomalacia which results in blindness. Vitamin A deficiency (VAD) is mainly observed among young children in developing countries and has been recognized to be a major controllable public health and nutritional problem. The main causes of childhood vitamin A deficiency in the developing countries include, maternal VAD resulting in low concentrations of vitamin A in breast milk, inadequate dietary intake of vitamin A after introduction of complementary feeding, and repeated episodes of common infectious illnesses like diarrhoea, measles and acute respiratory infection (ARI), which further decrease vitamin A levels. ${ }^{1}$ Recent evidence suggests that even mild deficiency of the micro nutrient probably increases morbidity and mortality among children, which signifies the public health importance of this disorder. In India, an estimated 5.75\% children suffer from eye signs of VAD. ${ }^{2}$ Improving this micronutrient status of deficient children through vitamin A supplementation (VAS) enhances their resistance to disease and can reduce mortality from all causes by approximately 23 per cent. Ensuring high supplementation coverage is therefore critical, not only for eliminating VAD as a public-health problem, but also as a central element of the child survival agenda. ${ }^{3}$

Government of India launched the National Vitamin A Prophylaxis Programme in 1970 for prevention of blindness in children of seven endemic States where children between six months to six years of age were to be administered mega doses of Vitamin A at six monthly intervals. During the early 1990s, this intervention was restricted to children between 9 months and 3 years, as clinical deficiency was almost exclusively restricted to this age range. Consequently the number increased to nine from the previous five mega doses. The first dose at nine months is given along with measles immunization. ${ }^{1,2,4}$ VAS is implemented through the primary health centres, its subcentres and the Anganwadis. ${ }^{2}$

Thus against this background, the present study was carried out to assess the coverage of prophylactic dosage of Vitamin A in Oil among children aged 9 months -59 months in Amdanga Block of West Bengal, to 
find out the villages (lots) which were poorly performing and to determine the reasons for non receipt of a mega dose according to the age of the child.

\section{Materials And Methods}

A descriptive, cross sectional study of coverage of Vitamin A in oil among children aged 9 months 59 months using Lot quality technique (LQT) was conducted in Amdanga Block in North 24 Parganas district of West Bengal from December 2012- January 2013. This block is the rural field practice area of the Department of Community Medicine, R.G. Kar Medical College, Kolkata, West Bengal, India.

2.1 Sample size estimation and sampling: The total population of Amdanga Block was 194882 in 2012. The proportion of children aged 0-59 months in rural West Bengal is 7.59\% of the total population. ${ }^{5}$ Since datum on proportion of children, aged $9-59$ months (target population) was not available, so the proportion of children within the age bracket 0- 59 months was considered for estimating the sample size. The target population in the block was estimated to be around 14792. Applying $\pm 5 \%$ desired level of accuracy and $99 \%$ desired level of confidence, the sample size was found to be 663 . The sampling fraction was $<10 \%(4.48 \%)$, hence the sample size of 663 was to be covered in 81 villages (lots). A lot sample size of 8.18 was calculated which was rounded to 9 (nearest whole number). ${ }^{6}$ So, the ultimate sample size achieved was 729 ( 81 lots X 9 children in each lot). The nine households in each lot were randomly selected in accordance with the guidelines of Lot Quality Technique. One target child was taken from each household. If any house was found locked, then the immediate next door was visited till a target child was found. Data were collected by the $1^{\text {st }}$ year MD students under the supervision of the Faculty members of the Department of Community Medicine. Informed consent was taken from the mother/caregiver of the child. The age of the child was assessed from documents like hospital discharge certificate/birth certificate/ Immunization card for the exact date of birth. The number of mega doses of Vitamin A in oil received by the child was noted from the Immunization card for documented evidence, in a pre designed, pre tested schedule. Decision value for lot sample size of 9 was set at 2, considering low threshold value of $30 \%$ and high threshold value of $95 \%$. Any village (lot) having more than 2 children with inadequate doses of Vitamin A in oil according to age was considered to be a poorly performing one. The reason of not getting the vitamin at an appropriate age was also ascertained by interviewing the respondent following the proforma of WHO. ${ }^{6}$ A dose of Vitamin A was considered valid if

i) The first dose was received within 12 months.

ii) Interval between two doses was at least six months. ${ }^{7}$

Data were entered into MS@ Excel 7 and analyzed using simple proportions and percentages. The estimated coverage was calculated after giving weight to each lot and multiplying by the proportion of children who received VAS. ${ }^{6} 95 \%$ Confidence Intervals were calculated and Chi square test was done to test statistical significance.

\section{Results}

Table 1 shows the distribution of the study subjects according to age and gender. Most of the study subjects were within the age bracket of 12-23 months followed by 24-35 months. The proportion of males and females in all the age groups were almost similar.

Only three children out of $729(0.4 \%)$ had received adequate doses of Vitamin A in oil according to their age. There was a lack of supply of Vitamin A in oil for the last one year from the time of survey. Hence, children who missed up to two doses were considered acceptable while computing the coverage (since it is administered at six monthly intervals). The proportion of children who missed $>2$ doses was $32.1 \%$ (234/729).The actual and estimated coverage among 729 children in 81 lots were $67.9 \%$ and $67.16 \%$ respectively. Out of 81 lots, the number of lots found to have less satisfactory performance based on the decision value of 2 was 48(59.2\%). (Not shown in table). Table 2 shows the coverage of valid doses of Vitamin $\mathrm{A}$ in oil among the beneficiaries. The coverage from the first to the third doses declined gradually, whereas the decrease in coverage for the subsequent doses is rather steep and it is $0 \%$ for the $8^{\text {th }}$ and $9^{\text {th }}$ doses. Out of 729 children, 284(38.9\%) did not receive a single dose of Vitamin A in oil. (not shown in table).

Tables 3 shows the distribution of the study subjects according to the number of missed doses of Vitamin A in oil versus age and gender respectively. It revealed that the children who missed more than two doses were significantly higher among children aged 36-59 months compared to that below 36 months (78.6\% vs $21.4 \%$ ), while no statistically significant association was found with gender. Table 4 presents the reasons for non receipt of a mega dose of Vitamin A in oil. Three children had up to date VAS. Thus the reasons for non receipt of a megadose were calculated on 726 children. Lack of supply of Vitamin A in oil was the commonest cause $(68.18 \%)$ for the same. 


\section{Discussion}

The present study noted extremely low coverage (0.4\%) of VAS at Amdanga Block, of West Bengal owing to lack of supply of the vitamin for the last one year. Thus the coverage was computed, taking into consideration missing of $\leq 2$ doses as acceptable. The actual and estimated coverage among 729 children in 81 lots were $67.9 \%$ and $67.16 \%$ respectively. UNICEF observed a coverage of $66 \%$ in India in 2011 with bi annual doses among children 6-59 months of age. ${ }^{8}$ The coverage with VAS in India in 2010 with one dose among 1259 months children was $20.2 \%$ while in West Bengal it was $36.5 \% .{ }^{9}$ In a similar study using Lot quality assurance sampling conducted by Mukhopadhyay et al at Darjeeling district in West Bengal in 2006 among 3-4 years children, the estimated coverage with five mega doses was found to be as low as $14.52 \%$. $^{7}$ In a study conducted by Sain et al among 150 children aged $60-72$ months in a slum of Kolkata, West Bengal in 2008, only $40.7 \%$ had completed all 9 doses of vitamin A. ${ }^{10}$ However the results of these studies are not befitting with that of the present one.

The coverage with a valid first dose of Vitamin A as revealed by this study was $57.6 \%$ and the same declined with subsequent doses, with a 'nil' coverage of $8^{\text {th }}$ and $9^{\text {th }}$ doses.(Table 2) Much of this could be attributed to the unavailability of Vitamin A in the health facilities. In West Bengal, in 2010-11, the coverage of Vitamin A in oil with $1^{\text {st }}, 5^{\text {th }}$ and $9^{\text {th }}$ doses, were found to be $82.38 \%, 83.23 \%$ and $34.64 \%$ respectively. ${ }^{11}$ The study carried out by Mukhopadhyay et al revealed a similar picture with coverage declining from the first to fifth doses. Though the coverage with the first dose was higher (65.7\%) compared to the present study, the same for the second to fourth doses were $(40.48 \%, 34.13 \%, 22.7 \%$ respectively) than what this study observed $\left(50.5 \%, 44.29 \%, 28.37 \%\right.$ respectively), while that for the $5^{\text {th }}$ dose was similar in both $(16.82 \%$ vs $16.67 \%)$ the studies. ${ }^{7}$ In a study conducted by Mandal etal in Bankura, the coverage with $1^{\text {st }}$ dose was $92 \% .{ }^{12}$ Yet, in another study conducted by Sachdeva and Dutta in Delhi municipality in 2005 using 30 cluster sampling, 37.6\% children received the first dose. ${ }^{13}$

This study revealed that the children who missed more than two doses were significantly higher among children aged 36-59 months compared to that below 36 months while there was no statistically significant difference as far as gender was concerned. (Table 3) A review of literature from 1991-2012 regarding VAS done by Bhutia etal also brought forth a likewise decreasing coverage with age - where coverage with one dose in the past six months was $45.4 \%$ among children aged 12-23 months; this decreased to $16.4 \%$ among children aged 36-47 months and then further to 9.4\% among children aged 48-59 months. ${ }^{9}$ In the studies conducted by Sain etal, Mandal etal and Sachdeva and Dutta, coverage was not significantly associated with gender, which was consistent with the finding of the current study. ${ }^{10,12,13}$

The non receipt of a megadose of the Vitamin was mainly due to lack of supply (68.8\%), followed by lack of time and knowledge of mothers (8.67\% and $7.44 \%$ respectively). However reluctance to return for just a dose if Vitamin A despite being aware, was also contributory in $6.47 \%$ of such cases. (Table 4 ) The study by Sain etal also depicted a similar scenario with inadequate supply, contributing to $70 \%$ while unawareness and inconvenient timings accounted for $20 \%$ and $10 \%$ of noncompliance. ${ }^{10}$

\section{Conclusion}

VAS is an important intervention addressing the issue of under five morbidity and mortality. The unavailability of Vitamin A in oil for over a year might prove detrimental to the progress towards the amelioration of child health indicators. The feasibility of alternate interventions like food fortification with the micronutrient at this stage for large scale implementation should be sought for. Thus extensive behavior change communication strategies addressing both beneficiaries and providers regarding improving the dietary intake of Vitamin A, regular attendance to ICDS centre and early identification of ocular signs and symptoms is required at present to mitigate the lack of supply.

\section{References}

[1]. Universal Vitamin A Supplementation Programme in India: The need for a re-look. The National Medical Journal Of India , Editorials. 2010;23(5):193-196

[2]. Ministry of Health and Family Welfare. India. November2006. http://motherchildnutrition.org/.../mcn-vitamin-a-ifasupplementation.pdf (accessed on 28.05.2013)

[3]. UNICEF 2007. Vitamin A supplementation - A Decade of Progress (New York 2007) $\mathrm{http} / /$ www.unicef.org/immunization/files/Vitamin_A_Supplementation.pdf (accessed on 15.09.2013)

[4]. Taneja D K. National Nutrition Programmes. Health Policies and Programmes in India. $9^{\text {th }}$ Edition (Doctors Publication, Janata Flats, Delhi, India 2011): 283

[5]. State Bureau of Health Intelligence, Government of West Bengal. Health on the March. 2010-11: 15

[6]. WHO/VRD/TRAM/96.01. Monitoring immunization services using the Lot Quality Technique. Department of vaccines and Biologicals (World health Organization. Geneva 1996): 7-18, 23, 25, 27, 58-59, 83

[7]. Mukhopadhyay DK, Mandal S, Sadhukhan SK, Chakraborty M, Lahiri SK. Vitamin A Deficiency and Coverage under National Programme in a SubHimalayan Rural Community of West Bengal Using Lot Quality Assurance Sampling. Indian J. Prev. Soc. Med 2007; 38(3\&4):197-201 
[8]. Child info-Monitoring the Situation of Women and Children (UNICEF 2013) http://www.childinfo.org/vitamina_coverage.php. (accessed on 15.09.2013)

[9]. Bhutia DT, Pee S, Zwanikken PAC. Vitamin A Coverage Among Under-Five Children A Critical Appraisal of the Vitamin A Supplementation Program in India. Sight and Life 2013;Vol. 27(1) : 12-19

[10]. Sain S, Mukhopadhyay P, Saha, TK, Ghosh R. Coverage with vitamin A oil supplementation and factors influencing its uptake among children residing in an urban slum in Kolkata. Int. J. Med. Public health. $2011 ; 1(4): 39-44$

[11]. http://www.wbhealth.gov.in/Health Stat/2010 2011/9/IX.11.pdf. (accessed on 28.05.2013)

[12]. Mandal NK , Sinhamahapatra B, Sinha $\bar{N}$, Mukhopadhyay DK, Das R, Biswas AB. Child Immunization and Vitamin A Supplementation in the District of Bankura, West Bengal. Int. J. Med. Public health 2011;1(3): 22-26

[13]. Sachdeva S, Datta U. Vitamin A-first dose supplement coverage evaluation amongst children aged 12-23 months residing in slums of Delhi, India. Indian J Ophthalmol. 2009; 57(4): 299-303

Table no. 1: Distribution of study subjects according to age and gender $(n=729)$

\begin{tabular}{|c|c|c|c|}
\hline \multirow{2}{*}{ AGE (in months) } & \multicolumn{2}{|c|}{ GENDER } & \multirow{2}{*}{ TOTAL } \\
\cline { 2 - 4 } & Male & Female & $54(7.4)$ \\
\hline$<12$ & $27(3.7)$ & $27(3.7)$ & $216(29.7)$ \\
\hline $12-23$ & $110(15.1)$ & $106(14.6)$ & $174(23.9)$ \\
\hline $24-35$ & $88(12.1)$ & $86(11.8)$ & $155(21.2)$ \\
\hline $36-47$ & $79(10.8)$ & $76(10.4)$ & $130(17.8)$ \\
\hline $48-59$ & $67(9.2)$ & $63(8.6)$ & $729(100)$ \\
\hline TOTAL & $371(50.9)$ & $358(49.1)$ & \\
\hline
\end{tabular}

Table no. 2: Coverage of valid doses of Vitamin $A$ in oil among the beneficiaries

\begin{tabular}{|c|c|c|}
\hline Vitamin A dose & Coverage (\%) & 95\% CI \\
\hline 1st & 57.6 & $55.29-58.21$ \\
\hline 2nd & 50.5 & $48.57-51.83$ \\
\hline 3rd & 44.29 & $42.12-46.5$ \\
\hline 4th & 28.37 & $24.74-29.95$ \\
\hline 5th & 16.67 & $13.66-18.88$ \\
\hline 6th & 5.41 & $3.42-7.98$ \\
\hline 7th & 1.58 & $0-4.76$ \\
\hline
\end{tabular}

* CI- Confidence Interval

Table no. 3: Distribution of study subjects according to the number of missed doses of Vitamin $A$ in oil by age and gender $(n=729)$

\begin{tabular}{|c|c|c|c|}
\hline \multirow[t]{2}{*}{ Variable } & \multicolumn{2}{|c|}{ Number of Missed doses (\%) } & \multirow[t]{2}{*}{ Significance } \\
\hline & $\leq 2$ & $>2$ & \\
\hline \multicolumn{4}{|l|}{ Age(in months) } \\
\hline $9-35$ & $394(79.6)$ & $50(21.4)$ & \multirow{3}{*}{$\chi^{2}=226.25$, d.f $=1, \mathrm{p}<0.001$} \\
\hline & & & \\
\hline $36-59$ & $101(20.4)$ & 184(78.6) & \\
\hline \multicolumn{4}{|l|}{ Gender } \\
\hline Male & $247(49.9)$ & $124(52.9)$ & \multirow{4}{*}{$\chi^{2}=0.61$, d.f $=1, p=0.43$} \\
\hline & & & \\
\hline Female & $248(50.1)$ & $110(47.1)$ & \\
\hline Total & $495(100)$ & $234(100)$ & \\
\hline
\end{tabular}

Table no. 4: Reasons for non receipt of a megadose of Vitamin $A$ in oil $(n=726)$

\begin{tabular}{|c|c|c|}
\hline Reason & Number & Percentage \\
\hline Unaware of need for Vitamin A supplementation & 6 & 0.83 \\
\hline Unaware of need to return for the next dose & 48 & 6.61 \\
\hline Fear of side effects & 2 & 0.28 \\
\hline Place of administration far away & 11 & 1.51 \\
\hline Inconvenient timing & 13 & 1.79 \\
\hline Absence of vaccinator & 4 & 0.56 \\
\hline Mother too busy & 63 & 8.67 \\
\hline Family problem including poor health of mother & 18 & 2.48 \\
\hline Child ill- not brought & 19 & 2.62 \\
\hline Lack of supply & 495 & 68.18 \\
\hline Others (Reluctance to come just for a dose of Vitamin A in oil) & 47 & 6.47 \\
\hline
\end{tabular}

